\title{
Neurilemmoma of the Parotid Gland
}

\author{
AKMR ISLAM ${ }^{\mathrm{a}}$, M MURSHID
}

\section{Summary:}

Nerilemmoma is well encapsulated tumour,which forms a single, round or fusiform firm mass on the course of a nerve.They arise from Schwann cells of neurilemma of nerves. These tumors often grow to a large size without

\section{Introduction:}

Neurilemmomas are benign, encapsulated tumors of the nerve sheath. Neurilemmoma arises from Schwann cells of neurilemma of nerves. The etiology is unknown. There is no gender predeliction. They may arise at any age, the peak incidence is between the third and sixth decades. The tumour is usually solitary, smooth surfaced, slow growing and generally asymptomatic. ${ }^{3}$

It may be benign or malignant. But, incidence of malignant neurilemmoma is rare.These tumours may be lagre enough without causing any neurological deficit. Once they do begin noticing symptoms, it is usually because the tumor has gotten big enough to see or feel, or large enough to begin compressing the nerve. If the tumor is palpable, it will often be sensitive to the touch. The neurilemmoma may also start causing pain due to nerve compression syndrome, also called compression neuropathy, or more commonly, a pinched nerve. Symptoms of this might include muscle weakness, numbness, pain, or a tingling sensation. This might explain the difficulty that physicians encounter in establishing a correct preoperative diagnosis. In this article, we will describe a case of this rare tumor with operative procedure and difficulties encountered during the procedure.

\section{Case report:}

A 20 years old young man was admitted to Gonoshasthaya Nagar Hospital with a left parotid

a. Prof. Dr. A.K.M Rezaul Islam, Professor and Head of the dept. of Surgery, Gono Shasthaya Samaj Vittik Medical College, Savar.

b. Dr. Munzur-E-Murshid, Intern Doctor, Gonoshasthaya Samaj Vittik Medical College Hospital, Savar, Dhaka.

Address of Correspondence: Prof.Dr.A.K.M Rezaul Islam, Professor and Head of the dept. of Surgery, Gono Shasthaya Samaj Vittik Medical College, Savar

Received: 29 January, 2013

Accepted: 10 September, 2013 causing any neurologic deficit. We report here a case of neurilemmoma of parotid gland showing histopathological findings of cellular neurilemmoma,in a 20 year old male patient.

(J Banagladesh Coll Phys Surg 2013; 31: 227-229)

swelling ,which had appeared 5 months earlier and which had been growing slowly and steadily. He had no other symptoms, his otolaryngologic and general physical examinations were completely normal. The lump was globular in shape; margin was rounded, firm in consistency, free from overlaying skin and underlying muscle. It was mildly tender. It was over the posterior margin of the mandibular ramus. The facial nerve function was normal on clinical evaluation. Ultrasonography of the gland revealed parotid cyst. FNAC of the parotid gland revealed neurilemmoma. The patient underwent a left total parotidectomy with a complete excision of the cyst. During the surgical procedure parotid gland was exposed. The superficial lobe was intact and the swelling was palpable within and deep to the deep lobe.

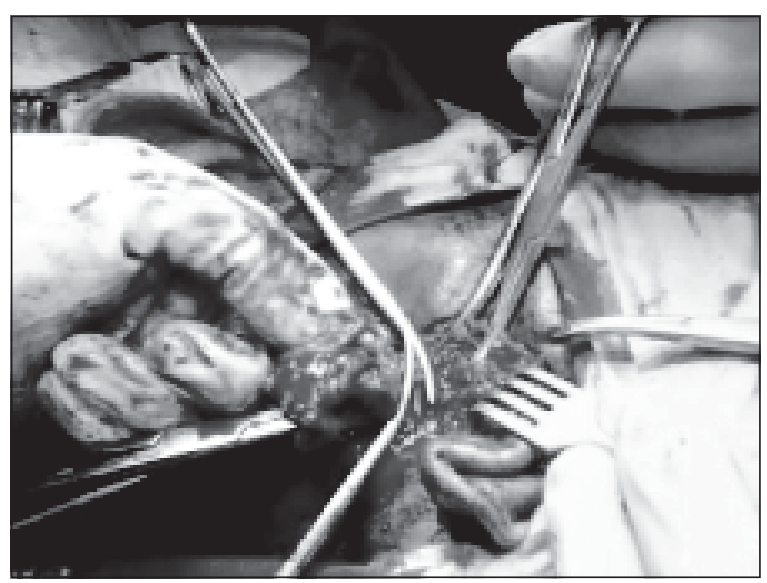

Fig.-1: Excision of the cyst

The deep lobe was exposed, keeping the facial nerve out of the harm's way. During dissection the cyst burst. Most of the cystic fluid came out during manipulation and rest of the fluid sucked out. Fluid was haemorrhagic due to pre-operative FNAC. The cavity was considerably deep and extended up to the wall of the 
pharynx. The cyst wall carefully separated from the surrounding tissue and removed along with deep lobe of the parotid gland. The zygomatic branch of the facial nerve which was adherent with the cyst was sacrificed. Haemostasis ensured and the wound closed in single layer leaving a drain in situ. The drain tube collection was 50 cc blood. The drain removed on third postoperative day. The parotid tissue and cyst were sent separately for histopathology. Histopathology of parotid tissue revealed no pathology but histopathology of cyst wall revealed Neurilemmoma. Patient was discharged from the hospital on $8^{\text {th }}$ POD with facial palsy involving the area supplied by zygomatic branch resulting in inability to close the left eye completely.

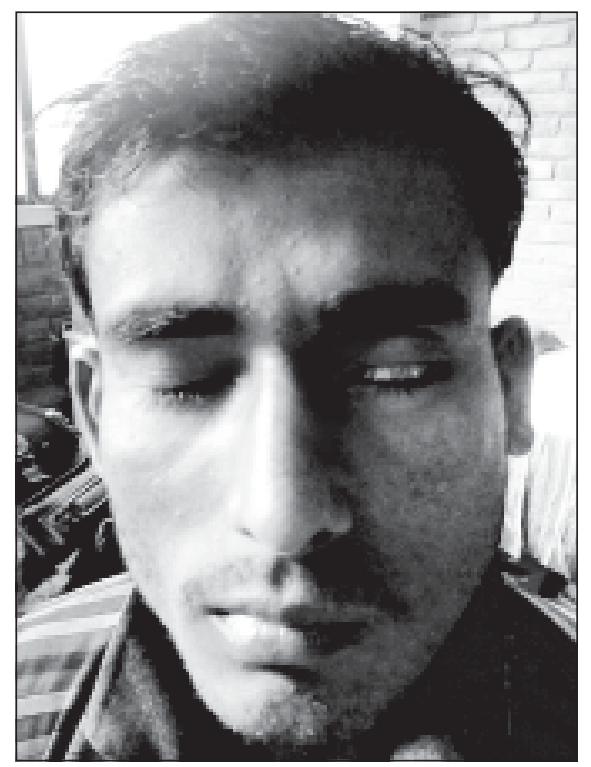

Fig.-2: Incomplete Closure of The Left Eye on 7th POD

\section{Discussion:}

Friedrich Theodor Schwann, described the neurilemma; the delicate outermost membrane of the myelin sheath of a myelinated nerve cell in $1839 .^{2}$

Verocay first described Neurilemmomas in1908, who later called them neurinomas. In 1935, Stout proposed the term neurilemmoma, believing that this type of tumor contains no neural elements but arises from the nerve sheath or Schwann's cells. According to Stout, only 194 adequately described neurilemmomas were reported in the literature during the 100 years prior to 1935 . Between 25 and $45 \%$ of all reported neurilemmomas have occurred in the head and neck region. ${ }^{5}$ Presenting symptoms of neurilemmoma are of three major types: (I) facial palsy or paresis; (2) otologic symptoms, and (3) parotid masses. These symptoms are stratified according to tumor location. ${ }^{6}$

The fact that these tumors often grow to a large size without causing any neurologic deficit is impressive. This might explain the difficulty that physicians encounter in establishing a correct preoperative diagnosis.

Facial nerve palsy complete or partial, can often be associated with neurilemmoma of the facial nerve. Neurilemmoma arises from Schwann cell of neurilemma which is ectodermal in origin. It is benign, well encapsulated tumour, which forms a single, round or fusiform firm mass on the course of a nerve. ${ }^{7}$ It is white to grey, firm and well capsulated lesion. If untreated, they can become large such an extent that can cause pressure symptoms.

Neurilemmomas are not associated with any known etiologic factor. It can arise at any age, although they do occur more often between the third and sixth decades of life.

Usually Neurilemmomas do not undergo a malignant transformation. However, some cases have been reported in the literature, which was mainly due to radiation therapy and the presence of neurofibromatosis (von Recklinghausen's disease); the incidence of malignancy among cases of neurilemmoma has been reported to range from 6 to 30\%. Facial nerve neurilemmomas are rather rare. Up until 1975, only 20 cases of intraparotid neurilemmoma had been reported in the English-language literature. Since then, 11 others have been reported. ${ }^{2}$

These tumors are soft and either white, yellow, or pink. They occasionally present with areas of calcification and/or cystic degeneration. Their capsule is continuous with the epineurium the most external nerve sheath.

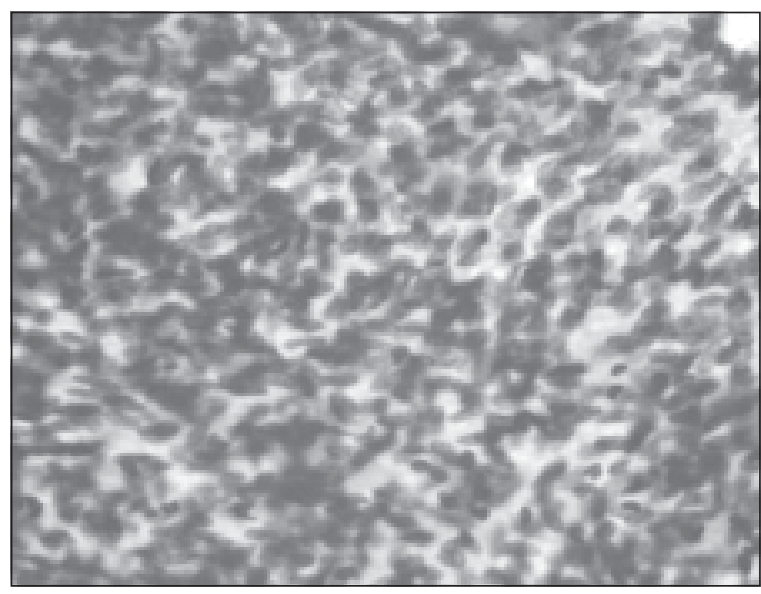

Fig.-3: Histopathological Features of Neurilemmoma 
Accurate preoperative diagnosis of neurilemmoma is important in order to advise the patient properly and plan the surgical approach. Unfortunately, it is also one of the most difficult aspects of managing patients with neurilemmoma. Many diagnostic tests have been recommended. Jackson et al" suggested directing the focus of radio- logic investigations to the perigeniculate region because this is the site of origin of most intratemporal facial nerve tumors. ${ }^{4}$

Histopathologically Neurilemmomas are characterized by a biphasic pattern of Antoni A areas and Antoni B areas. Antoni A areas are characterized by cellular spindle cells with indistinct cytoplasm which are arranged in intersecting bundles. Nuclei arranged in palisades around eosinophilic areas towards which the fibrillar cytoplasmic processes are oriented ( Verocay's body).Antoni B areas are characterized by abundant edematous stroma with microcystic formation \& loosely distributed cells.

Histopathological report in our case show cyst wall composed of spindle cells arranged in palisading pattern and in organoid arrangement.The cyst wall shows no lining epithelium. Areas of old haemorrhages are seen in the inner part of the wall.

The definitive treatment of a neurilemmoma is surgical excision $^{1}$. In these cases, as in our own, we readily identify the nerves; one facial nerve branch-zygomatic branch which was adherent with the cyst was sacrificed.

When a neurilemmoma arises from a major peripheral nerve, Seddon recommends enucleation by incision of the epineurium and dissection between the tumor capsule and the nerve fasciculi. ${ }^{2}$

Recurrence is rare with complete resections, and the overall prognosis of benign lesions is excellent.

\section{References:}

1. Singhal SK, Bansal S, Dass A,Tahlan A. Intra Parotid Facial Nerve Schwannoma: A Case Report. The Internet Journal of Otorhinolaryngology. 2005; 4(1). doi: 10.5580/1a1a.

2. Bates GJ. The ear. In: Willams NS, Bulstrode CJ, O’Connell PR, editors. Bailey \& Love's Short Practice of Surgery. $25^{\text {th }}$ ed. London. Hodder Arnold; 2008. p. 700.

3. Segas JV, Kontrogiannis AD, Nomikos PN, Boussiotou AH, Psarommatis JM, Adamopoulos GK. A neurilemmoma of the parotid gland: report of a case. Ear Nose Throat J. 2001 July; 8(7):468-70.

4. Dort JC, Fisch U. Facial Nerve Schwannomas. Skull base surgery. 1991 January; 1(1):51-56.

5. Das S. A Manual on Clinical Surgery. $7^{\text {th }}$ ed. Calcutta: S.Das; 2008. Chapter 3, Examination of a lump or swelling; p. 39.

6. Frosch MP, Anthony DC, Girolami UD. The central nervous system. In: Kumar V,Abbas AK, Fausto N, editors. Robbins and Cotran Pathologic Basis of Disease. $7^{\text {th }}$ ed. Philadelphia. Elsevier Saunders; 1999: 1411. 